\title{
Nearby farms are a source of lice for wild salmonids: a reply to Jansen et al. (2016)
}

\author{
R. M. Serra-Llinares ${ }^{1, *}$, P. A. Bjørn ${ }^{1}$, B. Finstad ${ }^{2}$, R. Nilsen ${ }^{1}$, L. Asplin ${ }^{1}$ \\ ${ }^{1}$ Institute of Marine Research, PO Box 6404, 9294 Tromsø, Norway \\ ${ }^{2}$ Norwegian Institute for Nature Research, PO Box 5685, 7485 Trondheim, Norway
}

\begin{abstract}
Jansen et al. (2016; Aquacult Environ Interact 8:349-350) question the regression analysis presented in Serra-Llinares et al. (2014; Aquacult Environ Interact 5:1-16), which correlates lice abundances on farmed and wild fish. Jansen et al. (2016) argue that the correlation might not reflect a cause-effect relationship but be instead a mere artifact of the spatio-temporal covariance in lice abundance on farmed and wild fish driven by temperature. In this Reply Comment we revisit the analysis presented in Serra-Llinares et al. (2014) and further re-analyze our data following the statistical approach used by Helland et al. (2015; Aquacult Environ Interact 7:267-280), to rule out the potential confounding effect of temperature. We conclude that Jansen et al. (2016) were correct in conveying part of the observed correlation to the effect of temperature; however, there is solid evidence of a significant influence of lice originating from nearby farms on the observed lice abundances on wild fish, even after the effect of temperature is accounted for.
\end{abstract}

KEY WORDS: Temperature $\cdot$ Salmon lice $\cdot$ Wild salmonids $\cdot$ Salmon farms $\cdot$ Lepeophtheirus salmonis

\section{Introduction}

Serra-Llinares et al. (2014) presented a correlation between the abundance of salmon lice Lepeoptheirus salmonis Kröyer on wild salmonids (sea trout Salmo trutta L. and Arctic charr Salvelinus alpinus L.) and the infestation pressure imposed by nearby farms, expressed as the daily release of copepodites (the infective stage of $L$. salmonis) within a $30 \mathrm{~km}$ distance from farmed sites. In their Comment Jansen et al. (2016) question these analyses, arguing that the correlation at issue might not reflect a cause-effect relationship, but merely be an artifact of the spatio-temporal covariance in lice abundance on farmed and wild fish driven by temperature (under consideration of pairwise timing and location of the data sets). In addition, Jansen et al. (2016) compare our results with those obtained by Helland et al. (2015), who were not able to predict lice numbers on

\footnotetext{
${ }^{*}$ Corresponding author: rosa.maria.serra.llinares@imr.no
}

wild salmonids using lice densities in nearby salmon farms when temperature was included in the analysis. Based on this premise, Jansen et al. (2016) question the validity of our conclusions regarding fish farms acting as a main source of lice for wild salmonids.

Salmon lice development rates are strongly dependent on water temperature; and lice levels on both farmed and wild fish fluctuate seasonally with temperature. Higher lice loads are typically recorded in summer compared to spring, regardless of distance to the nearest fish farms. This seasonal effect can indeed be seen in Fig. 2 and Tables $2 \& 3$ in Serra-Llinares et al. (2014). In addition, a spatial component might affect lice abundances on wild (Serra-Llinares et al. 2014) and farmed fish (Jansen et al. 2012). Hence we agree with the argument presented by Jansen et al. (2016): the need to account for the effect of temperature when analyzing factors that affect lice numbers on wild salmonids. We welcome

() The authors 2016. Open Access under Creative Commons by Attribution Licence. Use, distribution and reproduction are unrestricted. Authors and original publication must be credited. 
the chance to correct our analysis, and further use this opportunity to re-analyze our data following the statistical approach used by Helland et al. (2015) for direct comparison.

\section{Revisiting the analyses in Serra-Llinares et al. (2014)}

The role of temperature in the observed correlation between the infestation pressure from nearby farms and the observed lice abundances on wild salmonids in Serra-Llinares et al. (2014) was re-evaluated. The linear regression model presented in Serra-Llinares et al. (2014) was re-fitted using both the production of copepodites in nearby farms (calculated as specified in Serra-Llinares et al. 2014) and water temperature as predictors for the mean abundance of lice (all stages) on wild salmonids. In addition, partial correlation analysis on the same data was used to elucidate how much of the variance explained can be accounted for by infestation pressure itself. Prior to analysis mean lice abundances on wild fish $(\log +1)$ and estimated production of copepodites in nearby farms (log) were log-transformed. Data exploration (pairplots, Pearson's correlation and Variance Inflation Factors [VIF]) indicated no major collinearity between copepodite production in nearby farms and temperature $(\mathrm{r}=0.4, \mathrm{VIF}=1.17)$ (Zuur et al. 2010).

Results from the regression analysis revealed that both temperature and infestation pressure imposed by nearby farms (i.e. daily production of copepodites) have a significant effect on the mean abundance of lice observed on wild salmonids $(\mathrm{df}=72$, temperature: $p=0.004$, log-transformed daily production of copepodites: $\mathrm{p}<0.001$, $\mathrm{n}=75$ ), and together explained $37 \%$ of the variation on the log-log scale. Moreover, partial correlation analysis indicated that the production of copepodites in nearby farms by itself explained $21.8 \%$ of the variation in mean lice abundance on wild fish (on the log-log scale) while controlling for the effect of temperature $(\mathrm{p}<0.001, \mathrm{n}=$ 75). Model predictions for 3 different temperatures $\left(6,8\right.$ and $\left.10^{\circ} \mathrm{C}\right)$, representative of the range of temperatures present in the analyzed data set, show that the mean lice abundance on wild salmonids increased significantly with increasing infestation pressure from nearby farms, with temperature having an additive effect on this correlation (Fig. 1).
A potential pseudo-replication effect due to repeated sampling in the same locations was ruled out by comparing the results from a linear mixed effects model (using location as random intercept) and a generalized least squares model (i.e. a linear regression model without a dependency structure). Results indicate that adding a dependency structure did not improve the model (Akaike information criteria: 225 for the linear mixed effects model vs. 224 for the generalized least squares model), implying that the observed correlation between infestation pressure from farms, temperature and mean lice abundance on wild salmonids is not merely an artifact of pseudo-replication.

Note the difference in sample size between this reanalysis $(\mathrm{n}=75)$ and the analyzed sample size $(\mathrm{n}=$ 71) published in Serra-Llinares et al. (2014). Both analyses are based on the same data set (i.e. 75 data points), but 4 data points were removed from our original analysis (Serra-Llinares et al. 2014): 2 data points were mistakenly identified as outliers, and another 2 were lost after the direct log-transformation of the observed lice abundances on wild fish (without the addition of any constant prior to transformation). These errors have been corrected in this re-analysis, and the results continue to support our original conclusion that lice of farm origin are a main source of lice for wild salmonids.

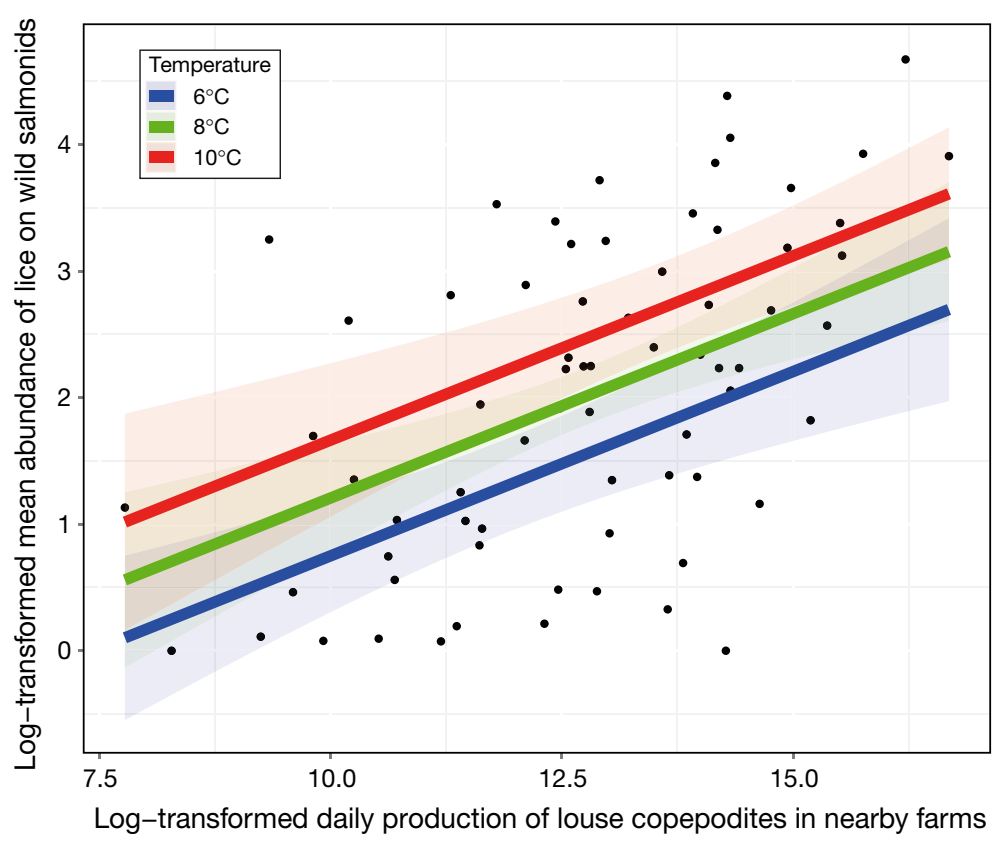

Fig. 1. Predicted mean abundances (fitted values with $95 \% \mathrm{CI}$ ) of lice (all stages) on wild salmonids as a function of the infestation pressure imposed by nearby farms (expressed as daily production of copepodites, calculated as explained in Serra-Llinares et al. 2014) at 3 different temperatures 


\section{Re-analysis using generalized linear mixed models}

Jansen et al. (2016) cite Helland et al. (2015) to argue that, once temperature has been included in the analysis, the relationship between the infestation pressure imposed by nearby farms and lice abundances on wild fish appears to be weaker than claimed by Serra-Llinares et al. (2014). Helland et al. (2015) and Serra-Llinares et al. (2014) analyzed comparable data sets. However, Helland et al. (2015) followed a very different statistical approach. Instead of using a summary statistic to describe the lice infestation levels observed on wild fish (such as mean lice abundance, as used by Serra-Llinares et al. 2014), Helland et al. (2015) used the actual number of lice (all stages) observed on each individual fish as the response variable in a generalized linear mixed model (GLMM), in which fish length, temperature, salinity and infestation pressure (expressed as the total number of mature female lice) from nearby farms were used as explanatory variables. We use this opportunity to re-analyze our data using GLMMs to directly compare our results to Helland et al. (2015) and to assess whether the concerns raised by Jansen et al. (2016) are justified.

We re-analyzed the data published in SerraLlinares et al. (2014) using a zero-altered negative binomial (ZANB) GLMM. In line with the zeroinflated negative binomial (ZINB) GLMM used by Helland et al. (2015), the ZANB GLMM deals with the high occurrence of zeros and the high over-dispersion in the observed data. The main distinction between the 2 approaches is the way the models interpret and analyze zero counts (more details are given in the Supplement at www.int-res.com/articles/ suppl/q008p351_supp.pdf).

The observed number of attached stages of lice (copepodites and chalimi, hereafter referred to as 'attached lice') on wild salmonids was used as response variable in the ZANB GLMM, instead of the total number of lice (all stages) used by Helland et al. (2015). Attached lice were preferred over the total number of lice since they are indicative of a recent and therefore more local infestation, whilst the total number of lice can be the result of an infestation pressure spanning much longer in time and space (Stien et al. 2005). Fish length, temperature, infestation pressure from nearby fish farms and year (categorical variable with the levels 2010 and 2011) were used as covariates in the ZANB GLMM. The interactions between each covariate and fish farm infestation pressure were also included. Location was used as a random effect to account for repeated measurements at the same location. No temporal auto-correlation was included in the analyses, because attached lice counted in Period 1 would have developed into preadult or adult stages by the time the second round of lice counting (Period 2) took place and thus both lice counts could be regarded as independent.

To make our results more comparable to those from Helland et al. (2015), we changed our infestation pressure variable from daily production of copepodites to total numbers of female lice in nearby farms. As in Serra-Llinares et al. (2014), only farms located less than $30 \mathrm{~km}$ from each wild fish sampling location were included in the calculation, and a linear correction was applied to account for the effect of distance. All wild fish sampling locations were included in this analysis, including those assumed to be free from lice of farm origin (i.e. those situated more than $30 \mathrm{~km}$ from the nearest fish farm). All details about the fitting and validation of the ZANB GLMM are given in the Supplement.

The ZANB GLMM was used to investigate the following 2 questions: What is driving the absence and presence of lice? And when lice are present, what is driving their numbers? Results from this analysis identified a significant effect of both temperature and infestation pressure from nearby farms on both the probability of having one or more lice (binary part of the ZANB GLMM) (Table 1 and Fig. 2) and on the intensity of the infestation (zero-truncated part of the ZANB GLMM) (Table 2 and Fig. 3), despite large variation around the fitted values.

Table 1. Summary from the Bernoulli generalized linear mixed model explaining the probability of presence of attached lice (measured as a binary response of either lice or no lice) on wild salmonids. Estimates for fish length $(\mathrm{mm})$, temperature $\left({ }^{\circ} \mathrm{C}\right)$ and infestation pressure refer to standardized values. Infestation pressure is expressed as the total number of female lice on nearby farms, linearly corrected by distance as explained in Serra-Llinares et al. (2014), and was square-root transformed prior to standardization

\begin{tabular}{|c|c|c|c|c|}
\hline & Estimate & $\mathrm{SE}$ & $z$ & $\mathrm{p}$ \\
\hline Intercept & -0.5937 & 0.31 & -1.89 & 0.058 \\
\hline Fish length & 0.0906 & 0.05 & 1.74 & 0.082 \\
\hline Temperature & 0.8134 & 0.09 & 9.06 & $<0.001$ \\
\hline Infestation pressure & 0.2695 & 0.15 & 1.81 & 0.071 \\
\hline Year 2011 & 0.6176 & 0.12 & 5.28 & $<0.001$ \\
\hline Fish length $\times$ Infestation pressure & -0.1848 & 0.05 & -3.51 & $<0.001$ \\
\hline Temperature $\times$ Infestation pressure & 0.3060 & 0.09 & 3.33 & $<0.001$ \\
\hline Infestation pressure $\times$ Year 2011 & 0.5900 & 0.15 & 4.06 & $<0.001$ \\
\hline
\end{tabular}




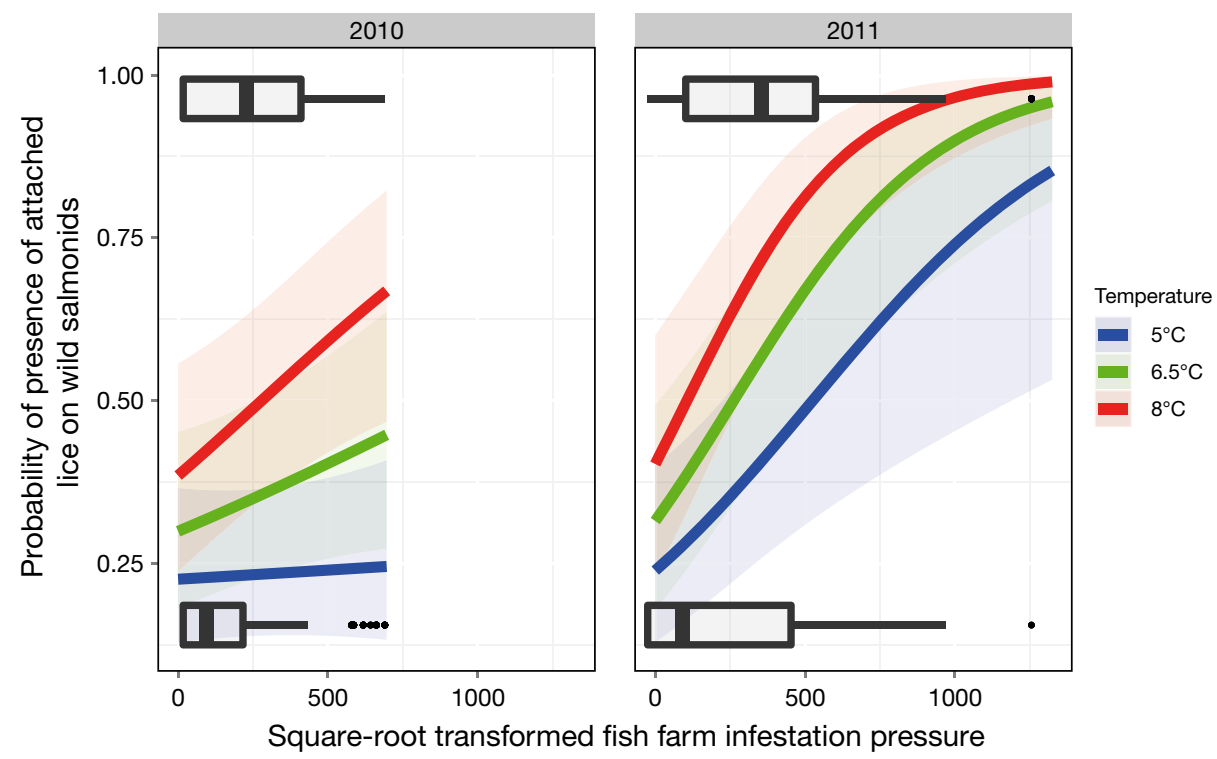

Fig. 2. Probability of presence of attached salmon lice on wild salmonids plotted versus infestation pressure imposed by nearby farms $(<30 \mathrm{~km})$ at 3 different temperature values, as predicted by the binary part of the zero-altered negative binominal generalized linear mixed model. Fish farm pressure is expressed as the total number of female lice on nearby farms, linearly corrected by distance as explained in Serra-Llinares et al. (2014). Boxplots show observed data: upper boxes represent fish farm infestation pressure values (square-root transformed) for fish with one or more attached lice; lower boxes infestation pressure values (square-root transformed) for fish with no attached lice. Dark horizontal lines represent median values, boxes the 25th and 75th percentiles, whiskers extreme values and black dots outliers

Although Helland et al. (2015) were not able to predict lice counts on wild fish, they state that 'even after correcting for the temperature effect, our results show that infestation pressure from salmon farms significantly increases the probability of wild sea trout having salmon lice' (p. 267). Thus, our results are in overall agreement with the findings of Helland et al. (2015). Here we provide further evidence of a significant influence of lice originating from nearby farms on the lice loads observed on wild salmonids, even after the effect of temperature is accounted for. There are many unaccounted sources of noise in the analyzed data set, which have the potential to reduce the statistical power of the analysis: variations in salinity

Table 2. Summary from the zero-truncated negative binomial generalized linear mixed model predicting numbers of attached lice on infested wild salmonids. For further information on variables see Table 1

\begin{tabular}{|lrrrr|}
\hline & Estimate & SE & \multicolumn{1}{c|}{$z$} & $\mathrm{p}$ \\
\hline Intercept & 2.11927 & 0.19 & 11.21 & $<0.001$ \\
Fish length & -0.05375 & 0.06 & -0.93 & 0.351 \\
Temperature & 0.52905 & 0.09 & 6.07 & $<0.001$ \\
Infestation pressure & 1.18889 & 0.19 & 6.26 & $<0.001$ \\
Year 2011 & 0.11261 & 0.13 & 0.90 & 0.371 \\
Fish length $\times$ Infestation pressure & 0.00915 & 0.04 & 0.22 & 0.830 \\
Temperature $\times$ Infestation pressure & 0.08006 & 0.08 & 1.02 & 0.306 \\
Infestation pressure $\times$ Year 2011 & -0.67073 & 0.18 & -3.75 & $<0.001$ \\
\hline
\end{tabular}

among sites, which have not been accounted for; variations in fish behaviour and host-parasite interactions among sampling sites; inaccuracy of temperature and lice infestation estimators (based on monthly reports); density-dependent effects on lice survival and/or host mortality; or potential for other wild fish species to act as reservoirs or vectors for sea lice, among others. A major limitation of the data is the over-simplification made when estimating the infestation pressure imposed by fish farms. On the one hand, a simple linear correction for distance does not reflect the real distribution of planktonic lice in the fjords, which is highly uneven and patchy as a result of their transportation with water currents (Asplin et al. 2014). On the other hand, neglecting the import and export of copepodites over distances $>30$ to $40 \mathrm{~km}$ might represent a critical error, particularly for locations closer to the coast (Asplin et al. 2014, Johnsen et al. 2014). There is currently no tool available to quantify the $\mathrm{R}^{2}$ of a ZANB GLMM (A. F. Zuur pers. comm.). However, fitted values from our models tend to be comparable to those obtained by a Poisson GLMM, which in this case explained $25 \%$ of the variance (see Supplement). This can be interpreted as a rather good fit given all the noise in the data set. 


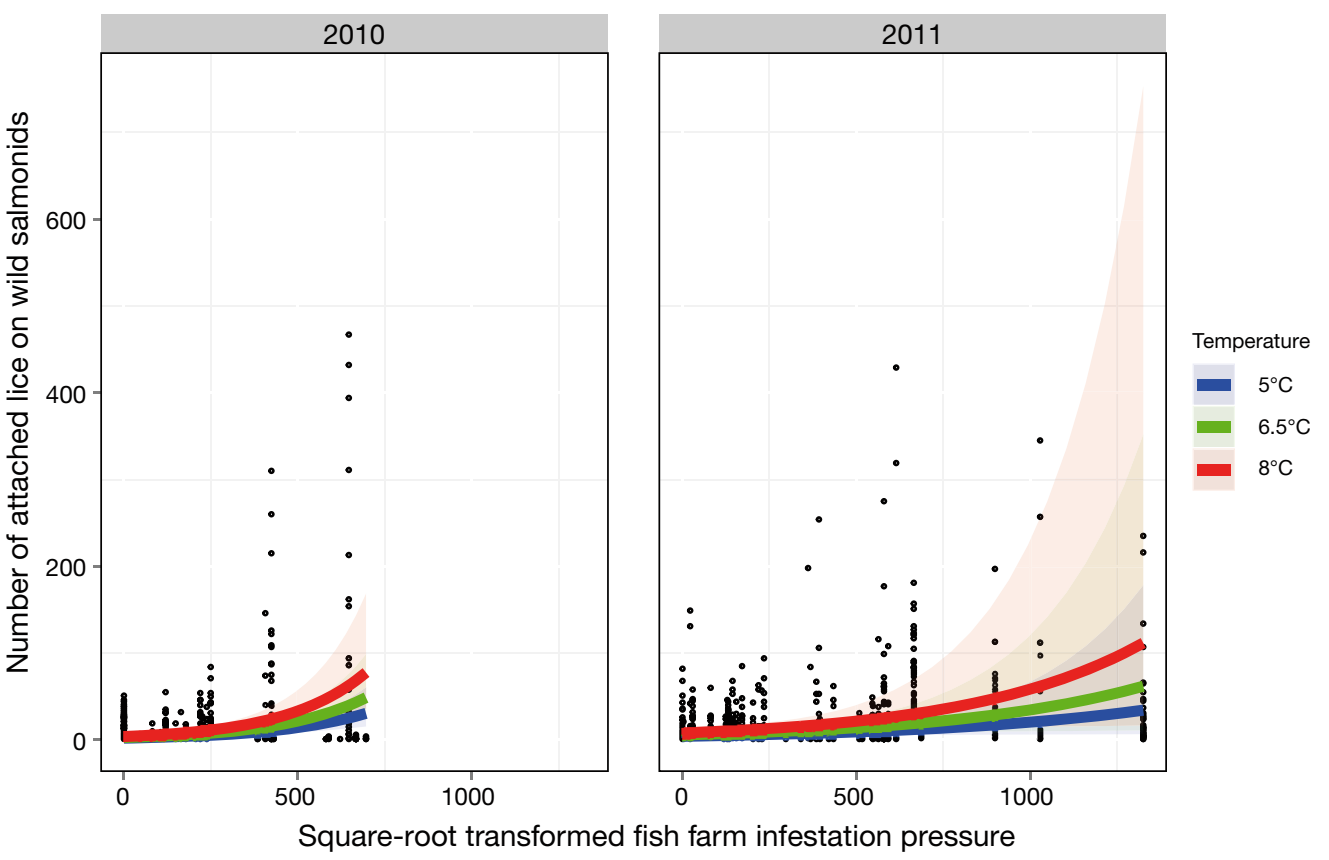

Fig. 3. Fitted values (with $95 \%$ CI) from the zero-truncated negative binomial generalized linear mixed model showing predicted attached lice counts on wild salmonids as a function of the lice infestation pressure imposed by nearby farms $(<30 \mathrm{~km})$ for 3 different temperature values. Fish farm pressure is expressed as the total number of female lice on nearby farms, linearly corrected by distance as explained in Serra-Llinares et al. (2014). Black dots show actual observed number of attached lice

\section{Concluding remarks}

Water temperature is an important modulator of salmon lice dynamics, as a regulator of the per capita reproductive rate of female lice (Stien et al. 2005). Therefore, it is natural to observe seasonal patterns in lice counts both on wild and farmed fish, with higher counts in summer compared to spring. However, water temperature has little influence on the total number of lice found at a particular location and time unless it is combined with a lice source (number of host fish and female lice per fish), irrespective whether they originate from wild or farmed fish. Norway is the world's largest producer of farmed Atlantic salmon, and farmed salmon production can exceed 10000 times the production of wild Atlantic salmon in some fjords (Skaala et al. 2014). Consequently, salmon farms ought to represent an important source of lice for wild salmonids, even when the numbers of female lice per farmed salmon may remain low.

In this Reply Comment to Jansen et al. (2016), we revisited the data published in Serra-Llinares et al. (2014), with a special focus on ruling out the potential confounding effect of temperature on the correlation between lice abundances on farmed and wild fish. First, we re-fitted the linear regression at issue (Fig. 3 in Serra-Llinares et al. 2014) including temperature as a covariate in the model. Second, we re-analyzed the data set using GLMMs to compare our results with those from Helland et al. (2015). Jansen et al. (2016, p. 2) conclude that 'if temperature is a confounder and there is no additional effect of farm origin lice as a factor that affects lice numbers in wild fish, then we would argue that there is no support in Serra Llinares et al. (2014) for the notion that lice of farm origin are a main source of infection in wild salmonids'. Results provided in this Reply Comment show that, even though Jansen et al. (2016) were correct in attributing part of the correlation between lice abundances on farmed and wild fish to the effect of temperature, there is strong evidence of a significant influence of lice originating from nearby farms on lice abundances on wild salmonids while accounting for the effect of temperature. In summary, our results from the analyses presented here and the results by e.g. Helland et al. (2015) and Thorstad et al. (2015) strongly suggest the transmission of lice from farm salmon to wild salmonids in systems where the fish occur in close vicinity. Future similar analyses should use available hydrodynamic-biological dispersal models (Asplin et al. 2014, Johnsen et al. 2016) to get a better estimate of the lice infestation pressure imposed by fish farms in different parts of the fjord systems along the Norwegian coast. 
Acknowledgements. We thank Alain F. Zuur (Highland Statistics) for carrying out the zero-altered negative binominal mixed model analysis.

\section{LITERATURE CITED}

Asplin L, Johnsen IA, Sandvik AD, Albretsen J, Sundfjord V, Aure J, Boxaspen KK (2014) Dispersion of salmon lice in the Hardangerfjord. Mar Biol Res 10:216-225

Helland IP, Uglem I, Jansen PA, Diserud OH, Bjørn PA, Finstad B (2015) Statistical and ecological challenges of monitoring parasitic sea lice infestations in wild salmonid fish stocks. Aquacult Environ Interact 7:267-280

> Jansen PA, Kristoffersen AB, Viljugrein H, Jimenez D, Aldrin M, Stien A (2012) Sea lice as a density-dependent constraint to salmonid farming. Proc R Soc B 279: 2330-2338

Jansen PA, Brun E, Skjerve E (2016) Salmon lice infection in wild salmonids in marine protected areas: Comment on Serra- Llinares et al. (2014). Aquacult Environ Interact 8: 349-350

Johnsen IA, Fiksen Ø, Sandvik AD, Asplin L (2014) Vertical salmon lice behaviour as a response to environmental conditions and its influence on regional dispersion in a

Editorial responsibility: Kenneth Black, Oban, UK fjord system. Aquacult Environ Interact 5:127-141

Johnsen IA, Asplin LC, Sandvik AD, Serra-Llinares RM (2016) Salmon lice dispersion in a northern Norwegian fjord system and the impact of vertical movements. Aquacult Environ Interact 8:99-116

Serra-Llinares RM, Bjørn PA, Finstad B, Nilsen R, Harbitz A, Berg M, Asplin L (2014) Salmon lice infection on wild salmonids in marine protected areas: an evaluation of the Norwegian National Salmon Fjords'. Aquacult Environ Interact 5:1-16

Skaala Ø, Sjøtun K, Dahl E, Husa V, Bjørge A, Uiblein F (2014) Interactions between Salmon Farming and the Ecosystem: Lessons from the Hardangerfjord, Western Norway. Mar Biol Res 10:199-202

Stien A, Bjørn PA, Heuch PA, Elston DA (2005) Population dynamics of salmon lice Lepeophtheirus salmonis on Atlantic salmon and sea trout. Mar Ecol Prog Ser 290: 263-275

Thorstad EB, Todd CD, Uglem I, Bjørn PA and others (2015) Effects of salmon lice Lepeophtheirus salmonis on wild sea trout Salmo trutta-a literature review. Aquacult Environ Interact 7:91-113

Zuur AF, Ieno EN, Elphick CS (2010) A protocol for data exploration to avoid common statistical problems. Methods Ecol Evol 1:3-14

Submitted: February 25, 2016; Accepted: April 6, 2016 Proofs received from author(s): May 6, 2016 